\title{
A Review of Spelling Errors in Arabic and Non-Arabic Contexts
}

\author{
Dheif Allah Hussain Falah Altamimi ${ }^{1}$, Radzuwan Ab Rashid ${ }^{1} \&$ Yasir Mohamed Mohamed Elhassan ${ }^{2}$ \\ ${ }^{1}$ Faculty of Languages and Communication, Universiti Sultan Zainal Abidin, Terengganu, Malaysia \\ ${ }^{2}$ Faculty of Languages and Translation-Sharoura, Najran University, Najran, Saudi Arabia \\ Correspondence: Radzuwan Ab Rashid, Faculty of Languages and Communication, Universiti Sultan Zainal \\ Abidin, Terengganu, Malaysia. E-mail: radzuwanrashid@unisza.edu.my
}

Received: May 15, 2018 Accepted: September 12, 2018 Online Published: September 14, 2018

doi: 10.5539/elt.v11n10p88 URL: http://doi.org/10.5539/elt.v11n10p88

\begin{abstract}
The purpose of this review paper is to identify the core spelling errors in Arabic and Non Arabic Contexts. The most common difficulty that Arab learners may face during their English writing is correct spelling, for many different reasons such as the interference between English and Arabic language and the irregularity of the English language system. Several studies have been undertaken to evaluate writing mistakes and spelling errors in English, and most of them have classified spelling errors into three different categories: morphemic errors, where the errors occur in the morphemes parts (prefixes and suffixes); Intra-Morphemic errors, where errors occur in the word roots themselves such as deleting the final (silent) e vowel in the word write, and splits types, where the learners leave a space inside the word for example, write my self as two words instead of myself, one word. Apart from the three categories mentioned above, other studies claim that there are eight different types of error related to the abilities of the students and the nature of the error, and these include inversion, omission, substitution, segmentation, insertion, pronunciation, miscellaneous, and unclassified errors. In this review paper, we have found interlingual and intralingual -related errors where interlingual errors are mainly caused by the interference of the primary or mother language, while, intralingual errors are due to the system and instruction of the target language. Finally, suggestions are given based on previous research about how to review the spelling errors in Arabic and Non Arabic contexts to identify the error and also overcome the problem through alternatives that can be implemented to create a positive impact and can be furthermore used for all types of positive learning.
\end{abstract}

Keywords: Arab, non Arab, interlingual error, intralingual error, spelling error

\section{Introduction}

Learning a foreign language always involves a number of challenges as indicated by Johnson (2008) and Rimbar (2017), especially, in the initial phases of learning, where learners make linguistic, syntactic, semantic and phonological errors. James (2013) states that these errors are a by-product of learning the language and they can be used as indicators of learning, as these errors can indicate at which phase of learning the learners are in. Conducting a systematic analysis of learners' errors could help indicate their needs for learning the language, so teaching can respond in a better way and learning occur at a faster pace. This analysis could further help in designing curricula, teaching plans and methods, and help the plans to eliminate some difficulties.

Writing is an essential system that enables individuals to express their feelings or thoughts when they cannot be spoken. It transfers the sounds that can be heard to words which can be read and seen. Enhancing literacy not only requires improving reading and writing skills but also the correct spelling of words. However, this pivotal component of writing is challenging for many students, particularly Arab students learning English. These learners are unable to spell English words correctly in many cases as they consider English is a foreign language and that they have no command over its pronunciation or spelling of words (Hauser, 2013).

Learning a second language is often challenging for learners as they construct some patterns or rules in the language they are learning according to which they pronounce and spell the words. A second language has patterns different from their native language/mother tongue which creates problems for learning another language. The patterns of an individual's first language become part of the linguistic instinct of that individual (Kocatepe, 2017). In order to learn any other language, the learner's linguistic instinct has to undergo various development stages and encounter with the second language, many times. During the process of development, 
the speaker listens to sounds which are different from his first language (L1) instinct and forms hypotheses about their use. Native speakers of a language have implicit knowledge about its orthographic structure, that is to say, native speakers pronounce or spell a word in their first language without overt knowledge of its rule (Dewaele \& Al-Saraj, 2015).

Among the various difficulties faced by Arab learners learning English, the most common error is related to the spelling of words used in documents. Students, due to ineffective learning, keep on repeating the same spelling errors even, when they have finished high school, university or have joined their area of work, which can create obstacles to their career progress. Therefore, spelling errors can handicap students in various ways. According to Ehri and Rosenthal (2010), accurate spelling goes along with learning the pronunciation of words. Their study suggests that a good command of spelling enables an individual to express his/her thoughts more conveniently and clearly in their writing. The most common errors when writing in English made by the Arab learners include final [e], vowels, silent letters and double consonants. These errors suggest language programmer writers and other stakeholders should focus on this predicament (Rohman, 2017).

Individuals who can spell well are free to express themselves in writing without being conscious of the mechanics of writing details all the time. Tinjacá and Contreras' (2008) study suggests that developing good spelling skills can help students to concentrate on the writing task rather than being distracted or afraid of committing spelling errors. Their study was based on the students of José Asunción Silva public school, Colombia with 1500 participants; among these were thirty-three tenth graders, sixteen female and seventeen male, between fifteen and nineteen years old. In this way, the final product written by students would be clearly understandable as there would be no excessive spelling errors. The occurrence of spelling errors affect the clarity of written work negatively and therefore; interfere the process of communication between what writer wanted to communicate and what the reader decodes (Fragman, 2015).

Apart from the negative impact spelling errors have on the quality if writing; they also closely relate the reading abilities of an individual. Some researchers, like Fender (2008) argue that bad spellers are bad readers as well. Some of the proponents of this argument such as Holmes and Quinn (2009) state that the causes of bad spelling are very similar to the causes of bad readers. Therefore, it is claimed that finding out the reasons for poor spelling and developing spelling skills could have positive impact on their reading as well as writing proficiency. Most Arab learners of English find it difficult to read writing in this foreign language. Due to this difficulty, readers pay too much attention to reading word by word, which slows the pace of their reading and cause them to stumble a lot (Kostelec Cvitkovič, 2016). This makes them unable to understand what they are reading because meaning comes from the relationship between words and the order of words. Word by word reading destroys this relationship and so negatively influences the performance of students in reading comprehension tests and their general reading proficiency (Qrqez, \& Rashid, 2017).

Poor spelling skills not only affect the literacy skills of the students. They also give a bad impression to colleagues or superiors in the workplace of weak spellers since they are perceived as careless or inadequately educated. Jayousi (2011) conducted a study of the spelling errors of Arab students, their types, causes, and teachers' responses when they corrected the spelling errors of 537 male students at four different education levels in public schools in the United Arab Emirates. He wanted to find out the perception of spelling errors of Arab learners. From his observations, the students at public schools in the United Arab Emirates seemed to have problems with spelling resulting in adverse effects on their overall language ability and success at school. He complained that teachers are not trained in how to teach spelling to students and they do not devote enough time to help the students learn properly and effectively. Moreover, the teachers have inaccurate concepts relating to the nature of the problems arising from poor spelling - its causes and methods to address these issues. In the light of the above discussion, researchers have found it important to discover the causes of spelling errors made by Saudi University students, the type of mistakes made and how they affect the overall academic as well as professional performance of the students (Naif \& Saad,2017).

Considering the significance of learning the English language and the negative effects of being unable to learn it well, it seems that English spelling creates a clear problem for most learners. Spelling is relatively more complicated for Arab learners due to the linguistic difference between their native language i.e. Arabic, and the froing target language of English. For instance, the writing systems and symbols are quite different. Consequently, it is expected that the spelling errors made by Arabic learners would differ from those of learners from other language backgrounds and therefore, the teaching methods required for Arab learners of English would also be different. 


\section{Studies of Spelling Errors in the Arabic Context}

Several studies have been conducted with different students of universities or academic institutions in Saudi Arabia to evaluate the spelling errors and writing mistakes in terms of English language. The majority of these studies examined and analyzed the written compositions submitted to the course supervisors or instructors. The studies classified errors into three different categories; Intra-morphemic, Morphemic, and Splits. Kao (2013) suggests that there are five different types of Morphemic error, as follows.

In errors of omission, the student fails to complete the word. However, in derivation errors, the student fails to apply basic rules and instructions for spelling a particular word i.e. they write snobbish as snobish. In inflection errors, the student ignores and does not perform the necessary changes while adding the inflection. For instance, students forget to drop the "e" when adding "ing" to some words, i.e. timeing for timing or reduceing for reducing. Under the category of residue error, students forget to drop letters in the right context or meaning for that specific word, i.e. bit for bite. Similarly, phonetic errors is where student spell words as they are pronounced e.g. yacht as yech or watched as watcht (Rass, 2015).

Sawalmeh (2013) investigated whether the occurrence of errors decreases as the student moves to a higher standard of education and developing a stronger understanding of the foreign or target language. The study was conducted on the Saudi students majoring in English and analyzed examination papers. Al-Khairy (2013) categorized errors into eight different types based upon the nature of the errors and ability of the students: 1) Inversion (reversing the position of two adjacent letters); 2) Omission (deletion of a letter), 3) Substitution (substituting one or more letters), 4) Segmentation (dividing or breaking a word into two), 5) Insertion (addition of an extra letter within a word), 6) Pronunciation (words misspelled due to their written from being different from their pronunciation), 7) Miscellaneous (mixture of errors that consist of multiple characteristics - making the words unreadable), 8) Unclassified errors (misspelled words that are illegible and contain no specific explanation). Al-Khairy's study revealed that the majority of the errors were concentrated in addition errors, omission errors and substitution errors.

Similarly, Daif-Allah (2012) also significantly contributed to the identification and analysis of spelling errors made by foreign language learners. This study identified six different major causes that lead students to make mistakes and errors while reading, spelling, and writing in the English language. However, the study does not include a clear analysis of the major reasons or causes. Some of the errors are caused by difference in the sound system of Arabic and that of English , i.e. some of the Arab students spell words in the way they pronounce them (Yan,2010). Some sounds are not included in the Arabic system such as "v" and "p", so pronunciation errors are due to the extra sounds in the English language system or written forms which are not pronounced or the same sounds with different written forms (by and buy). This includes most with homophones or schwa. Sometimes the arbitrary and inconsistent nature of English word derivation causes the majority of misspelled words and spelling mistakes, i.e. receive-reception, describe-description, and wife-wives. Generalizing from a rule can also lead to errors in spelling, i.e. analyse as analize or women as womans (Umera-Okeke, 2008). The lack of knowledge or the incomplete or inadequate application of English spelling rules also positively contributes to the occurrence of errors in writing. Furthermore, the study also suggests some personal attributes as reasons for multiple spelling errors or mistakes. Boredom, tiredness, and carelessness were the identified and recognized as increasing the chances of spelling errors in students of Saudi universities (Sharma, 2015).

Kang and Han (2015) highlight three major causes - interlingual, intralingual, and developmental - of errors made by Saudi students in written communication. As defined by Alhaysony (2012), interlingual errors are caused by interference from the primary language or mother tongue; however, intralingual errors are due to the system and instructions of the target language. On the other hand, the developmental errors are the outcome or results of the learner's developmental process or stage. In addition to these errors, Solati (2014) also pointed out that every individual error may have a number of causes. In the context of interlingual or interlanguage errors, the first cause Mahmoud (2014) found was interlanguage or interlingual errors of four different types:

1) Vocalic transfer: In this category, Arab students show lack the knowledge of how to use the correct vowel in the appropriate manner. The learners tend to use vowels abundantly without considering about the rules for vowel use or elementary knowledge of the immense differences between Arabic and English. The results showed that Arab students tended to use high front vowels and reduce all the mid and front high vowels. Additionally, Arab students tend to use mid central vowels to replace mid and mid-front vowels, and use high back vowels to replace all mid and back high vowels. For example, instead of writing "much", majority of the Arab students wrote "mach".

2) Consonant replacement: Arab learners tend to substitute letters with an available equivalent or counterpart. 
For instance, Arabic does not have the letter "p" in written format, so many Arab students replaced it with another voiced bilabial "b" that is available within the Arabic system. In many the cases, Arab learners wrote groubs for groups (Alghonaim, 2014).

3) Epenthesis errors: Since Arabic has very few consonant clusters, students tended to use a vowel to break up a cluster of consonants. For instance, tempting was written as tempiting by many Arabic-speaker learners or students.

4) Lastly, nativisation errors: Arabic students write or spell words in the way borrowings from English are pronounced and spelled in Arabic, e.g. Amreca as America.

The second groups of errors characterized by Alhaysony (2012) are developmental errors or learner-language errors in five different categories:

1) Cluster Simplification: The error occurs in a word where two adjacent consonants are shortened or simplified by dropping one of them, e.g. Island as ilan, Assimilation errors.

2) Where the pronunciation of the following or preceding sounds influence a change in graphemes. For instance, the sound or noise in the environment changes the pronunciation of " $\mathrm{t}$ " as " $\mathrm{d}$ " in the word "great".

3) Metathesis: In these errors the positions of two letters are reversed or inverted, i.e. students wrote first as frist.

4) Syllable Truncation and Syllable Simplification is where a syllable is omitted either completely or partially, e.g.. Excellent as ecslant.

5) Epenthesis errors are where a final consonant is added or removed in a word based upon the phonetic features of the previous phoneme, i.e. mined as mine

The final cause investigated within the study of errors is intralingual errors, divided into three different

types. Firstly, Graphemic Unification is where the majority of students misspell the letters "c" and "g" as " $s$ " and " $j$ ", for instance, college is represented as calleje or choice as shoise. Secondly, Monographicisation is where graphemes clusters represent the pronunciation of a word in the most simplified manner, e.g. foreign as foren. Thirdly, Phoneme/Grapheme Matching errors are made in context of misspelled vowels, e.g. other is written as ather (Hassan et al., 2014).

\section{Studies of Spelling Errors in a Non- Arabic Context}

Wang and Jiang (2015), claim that the initial cause of spelling errors is lack of concentration during the writing process despite students formally knowing the correct spelling or alphabetical sequence. The study also concluded that this type of spelling error occurs equally among students belonging to different grades at university. Some of the major spelling errors included; 1) adding or repeating the wrong letter within a word e.g. doubles as doubble or foundation as founddation; 2) omitting a letter or number of letters, e.g. conversation as conversion or interference as interface; 3) Transposing letters, that ring is placing a letter twice earlier in a word, e.g. Observation as Obsertvation or conversation as convertsation (earlier as well as in the correct position 4) doubling the wrong alphabet or letter, e.g. speed as spped or spell as speel; 5) the carelessness in writing similar letters, e.g. " $n$ " instead of " $m$ ", or b"" instead of "d"; and 6) substituting one letter with the wrong letter, writing, e.g. boat as boad or fog as fod. Sometimes, students forget some part of a word or substitute a word with another word with a similar meaning but not in the relevant context. The error of interference of association, the confusion similar kind of words, can cause misspelling a word, e.g. bored as board or then as than or and as end (Brosh, 2015).

Van, Jong and Kuiken, (2012) also claim the other causes of errors that student made in their examinations were related to incorrect observation. Inadequate reflection or observation about the word made it hard for the student to interpret or spell it correctly. Hence, they wrote it as they pronounced it, leading them to make lots of mistakes or errors (Highet, 2017). This classification of errors includes a number of categories discussed in the following paragraphs.

Spelling words in a similar way to its pronunciation, e.g. Wednesday as Wensday or lieutenant as leftenend. Sometimes, the colloquial speech or spelling errors of their instructors also leads students to mispronounce then write words incorrectly, e.g. chimney is written as chimley. Doubling the wrong single letter in a word, i.e. until as untill; reversing pairs of letters, in different words, i.e. ei and ie in receive and believe; inappropriate, incorrect and improper homonyms, i.e. fair as fare, bare as bear, or sight as site. Substituting the letter of one word by another with common visual features, e.g. doing as doiny or veil as veit. Due to wrongly perceiving or not hearing a word correctly, spelling errors occur during taking lecture or discussion notes. Some spelling errors are due to partial or total ignorance of words heard by students, i.e. geograthathy instead of geography (Attia et al., 
2014).

According to Saigh and Schmitt (2012), the spelling mistakes in the first stage of English learning can be prevented by establishing the appropriate learning environment for the learners. This environment can support and encourage the students to develop individual habits for testing their accuracy through self-assessment processes before submitting writing to the course instructor (Sharma, 2015). Self-evaluation helps students to look for their spelling mistakes more conscientiously in order to reduce the likelihood of making the same mistakes again in future examinations. On other hand, the errors in the second are mostly caused due to the ignorance of the words and consequent wrong phonetic spelling. These kinds of errors are reduced by paying close attention through repeatedly reading difficult or misspelled words with the correct guidance and phonetic pronunciation supervision (Meng, 2017).

The study of English errors by Van, Jong and Kuiken (2012) also suggests that students with different first languages can reduce their guesswork or estimates in writing down the correct spelling, by focusing on the difficult and complex words to eliminate the errors in those words in reading, spelling and writing contexts. Moreover, better visual analysis and evaluation of the letters needs to be done for using the correct letter in the right place. Forming an association between the correct pronunciation, written form and awareness of the meaning can also help prevent the same sort of spelling errors in future (Al-Busaidi \& Al-Saqqaf, 2015).

Thomas (2013) also analyzed the spelling errors of non-native speakers - Swedish and Finnish students - in their written English. The study pointed out that Finnish has more direct correspondence between symbols and sounds (near-phonemic) compared to Swedish so the results would be expected to be different for the 2 groups of students. How much the mother language is distanced from the target language in terms of spelling proficiencies, skills, and knowledge may also affect learner development. According to Polio (2012), the spelling errors can be classified as occurring because their spellings do not match their pronunciation. This category entails two further subcategories, described in the paragraphs that follow.

Omission, substitution of a sounded letter, i.e. Producing words that do not exist in English, e.g, satting for setting or jatting for chatting, also creates spelling problems. Confusion between different forms of a root word, i.e. do for did or does, or letter transposition, e.g. quite for quiet. On other hand, Polio's second category (2012) also embodies two subcategories for wrongly spelled words due to mispronunciation which break English spelling rules, .eg. admits as admits or says as sais or ignore silent letters i.e. nife for knife or soften as sofen. Misspelling some common words can cause confusion and misunderstanding, e.g. were for where or overgeneralizing English sound patterns, e.g. the homophone in receive as receave. This sub-category also includes spelling errors caused by letter substitution, e.g. decide as deside (Akkus \& Benmamoun, 2016).

\section{Conclusion}

Existing research suggests that English spelling and vocabulary is one of the most critical challenges for Arab learners, resulting in them making a lot of spelling errors and mistakes. Furthermore, the research also suggests that spelling errors negatively impact the writing proficiencies of the students and their written comprehensibility. Furthermore, a number of studies also suggest a positive relationship between students' reading ability and its reflective influence on their spelling and writing proficiency. If students can successfully overcome their errors and develop strong spelling abilities, this can influence their target language proficiency in all its aspects and features.

\section{References}

Akkuş, F., \& Benmamoun, E. (2016). Clause Structure in Contact Contexts: the Case of Sason Arabic. Perspectives on Arabic Linguistics, 153-172.

Al-Busaidi, S., \& Al-Saqqaf, A. H. (2015). English Spelling Errors Made by Arabic-Speaking Students. English Language Teaching, 8(7), 181. https://doi.org/10.5539/elt.v8n7p181

Alghonaim, A. (2014). Saudi university students' perceptions and attitudes towards communicative and non-communicative activities and their relationship to foreign language anxiety. Research Journal of English Language and Literature, 2, 83-101.

Alhaysony, M. (2012). An analysis of article errors among Saudi female EFL students: A case study. Asian Social Science, 8(12), 55. https://doi.org/10.5539/ass.v8n12p55

Al-Khairy, M. H. (2013). English as a foreign language learning demotivational factors as perceived by Saudi undergraduates. European Scientific Journal, 9(32).

Attia, M., Al-Badrashiny, M., \& Diab, M. (2014). Gwu-hasp: Hybrid Arabic spelling and punctuation corrector. 
In Proceedings of the EMNLP 2014 Workshop on Arabic Natural Language Processing (ANLP) (pp. 148-154). https://doi.org/10.3115/v1/W14-3620

Brosh, H. (2015). Arabic spelling: Errors, perceptions, and strategies. Foreign Language Annals, 48(4), $584-603$. https://doi.org/10.1111/flan.12158

Daif-Allah, A. S. (2012). Beliefs about foreign language learning and their relationship to gender. English Language Teaching, 5(10), 20. https://doi.org/10.5539/elt.v5n10p20

Dewaele, J. M., \& Al-Saraj, T. M. (2015). Foreign Language Classroom Anxiety of Arab learners of English: The effect of personality, linguistic and sociobiographical variables. Studies in Second Language Learning and Teaching, 5(2), 205-228. https://doi.org/10.14746/ssllt.2015.5.2.2

Ehri, L. C., \& Rosenthal, J. (2010). Spellings of words: A neglected facilitator of vocabulary learning. In Literacy Development and Enhancement Across Orthographies and Cultures (pp. 137-152). Springer, Boston, MA. https://doi.org/10.1007/978-1-4419-0834-6_10

Fender, M. (2008). Spelling knowledge and reading development: Insights from Arab ESL learners. Reading in a foreign language, 20(1), 19.

Fragman, A. (2013). Spelling accuracy of consonants in Arabic among Negev Bedouin students. Open Journal of Modern Linguistics, 3(04), 330. https://doi.org/10.4236/ojml.2013.34042

Hauser, E. (2013). Stability and change in one adult's second language English negation. Language Learning, 63(3), 463-498. https://doi.org/10.1111/lang.12012

Highet, K. (2017). How to do your Research Project: A Guide for Students in Education and Applied Social Sciences. Educate, 17(1), 26-27.

Holmes, V. M., \& Quinn, L. (2009). Unexpectedly poor spelling and phonological-processing skill. Scientific Studies of Reading, 13(4), 295-317. https://doi.org/10.1080/10888430903001225

Hussien, A. M. (2014). The effect of learning English (L2) on learning of Arabic literacy (L1) in the primary school. International Education Studies, 7(3), 88. https://doi.org/10.5539/ies.v7n3p88

James, C. (2013). Errors in language learning and use: Exploring error analysis. Routledge.

Jayousi, A., \& Thaher, M. (2011). Spelling errors of Arab students: Types, causes and teachers' responses (Doctoral dissertation).

Johnson, K. (2013). An introduction to foreign language learning and teaching. Routledge.

Kang, E., \& Han, Z. (2015). The efficacy of written corrective feedback in improving L2 written accuracy: A meta-analysis. The Modern Language Journal, 99(1), 1-18. https://doi.org/10.1111/modl.12189

Kao, C. W. (2013). Effects of Focused Feedback on the Acquisition of Two English Articles. TESL-EJ, $17(1), 1$.

Kocatepe, M. (2017). Female Arab EFL Students Learning Autonomously Beyond the Language Classroom. English Language Teaching, 10(5), 104. https://doi.org/10.5539/elt.v10n5p104

Kostelec Cvitkovič, M. (2016). E-Learning Materials in Teaching English as a Second Language. Proceedings of The 4th Global Virtual Conference. https://doi.org/10.18638/gv.2016.4.1.780

Mahmoud, A. (2014). The Use of Logical Connectors by Arab EFL University Students: A Performance Analysis. International Review of Social Sciences and Humanities, 7(1), 176-188.

Meng, Y. Y. (2013). Written corrective feedback: A review of studies since Truscott. Teachers College, Columbia University Working Papers in TESOL \& Applied Linguistics, 13(2), 69-84.

Naif, A. H., \& Saad, N. S. M. (2017). Language Learning Strategies Use and Challenges Faced by Adult Arab Learners of Finnish as a Second Language in Finland. English Language Teaching, 10(4), 111-126. https://doi.org/10.5539/elt.v10n4p111

Polio, C. (2012). The relevance of second language acquisition theory to the written error correction debate. Journal of Second Language Writing, 21(4), 375-389. https://doi.org/10.1016/j.jslw.2012.09.004

Qrqez, M., \& Rashid, R. A. (2017). Reading Comprehension Difficulties among EFL Learners: The Case of First and Second Year Students at Yarmouk University in Jordan. Arab World English Journal, 8(3), 421-431. https://doi.org/10.24093/awej/vol8no3.27

Rass, R. A. (2015). Challenges face Arab students in writing well-developed paragraphs in English. English Language Teaching. https://doi.org/10.5539/elt.v8n10p49 
Rimbar, H. (2017). The influence of spell-checkers on students' ability to generate repairs of spelling errors. Journal of Nusantara Studies, 2(1), 1-12.

Rohmah, I. I. T. (2017). Classroom Interaction in English Language Class for Students of Economics Education. Arab World English Journal, 8(2). https://doi.org/10.24093/awej/vol8no2.14

Saigh, K., \& Schmitt, N. (2012). Difficulties with vocabulary word form: The case of Arabic ESL learners. System, 40(1), 24-36. https://doi.org/10.1016/j.system.2012.01.005

Sawalmeh, M. H. M. (2013). Error analysis of written English essays: The case of students of the preparatory year program in Saudi Arabia. English for Specific Purposes World, 14(40), 1-17.

Sharma, V. K. (2015). How do productive skills of Saudi students affect EFL learning and teaching. Asian Journal of Humanities and Social Sciences (AJHSS), 3(2), 91-99.

Solati, A. (2014). Psycholinguistic sources of English spelling errors. International Journal of Teacher Education.

Umera-Okeke, N. (2008). Spelling and Phonetic Inconsistencies in English: A Problem for Learners of English as a Foreign/Second Language. African Research Review, 2(1), 64-83. https://doi.org/10.4314/afrrev.v2i1.41025

Van Beuningen, C. G., De Jong, N. H., \& Kuiken, F. (2012). Evidence on the effectiveness of comprehensive error correction in second language writing. Language learning, 62(1), 1-41. https://doi.org/10.1111/j.1467-9922.2011.00674.x

Wang, T., \& Jiang, L. (2015). Studies on Written Corrective Feedback: Theoretical Perspectives, Empirical Evidence, and Future Directions. English Language Teaching, 8(1), 110-120.

Yan, H. (2010). Study on the causes and countermeasures of the lexical collocation mistakes in college English. English Language Teaching, 3(1), 162. https://doi.org/10.5539/elt.v3n1p162

\section{Copyrights}

Copyright for this article is retained by the author(s), with first publication rights granted to the journal.

This is an open-access article distributed under the terms and conditions of the Creative Commons Attribution license (http://creativecommons.org/licenses/by/4.0/). 